\title{
Metabolic Studies on Two Patients with Nonhepatic Tyrosinemia Using Deuterated Tyrosine Loads
}

\author{
K. F. FAULL, I. GAN, AND B. HALPERN \\ Chemistry Department, University of Wollongong, Wollongong, Australia \\ J. HAMMOND, S. IM, R. G. H. COTTON, AND D. M. DANKS ${ }^{(26)}$ \\ Genetics Research Unit, Royal Children's Hospital Research Foundation, Melbourne, Australia
}

R. FREEMAN

Royal Children's Hospital, Melbourne, Australia

\begin{abstract}
Summary
Metabolic studies on two patients with defects in the tyrosine oxidation pathway are reported. Serum tyrosine was greatly elevated in both patients $(1.37$ and $1.52 \mathrm{mmol} / \mathrm{liter}$, respectively) and both excreted large quantities of $p$-hydroxyphenylacetic acid, $p$-hydroxyphenyllactic acid, and $p$-hydroxyphenylpyruvic acid. Deuterated tyrosine loads were administered to both patients, before and after lowering of the serum tyrosine concentration by dietary treatment, and to a normal adult control subject.

In one patient the excretion of the deuterated $\left(D_{2}\right)$-tyrosine load was more than 300 times that found in the control subject whether the test was done at high or low serum tyrosine level and the pattern of metabolites indicated a persistent defect in $p$ hydroxyphenylpyruvic acid oxidase. Enzyme assays on needle liver biopsy supported this finding. In the second patient excretion of the $D_{2}$ label was 300 times that of the control at high serum tyrosine levels, but only 5 times normal at low serum tyrosine levels. This finding was interpreted as indicating substrate inhibition of $p$-hydroxyphenylpyruvic acid oxidase. The primary defect has not been established in this patient, but the findings are compatible with a defect in hepatic-soluble tyrosine aminotransferase.
\end{abstract}

\section{Speculation}

We have shown that loading rates of $220 \mu \mathrm{mol}$ deuterated tyrosine/kg body weight are adequate for precise measurement of the stable isotope content of urinary tyrosine and tyrosine metabolites. This load approximates that provided by a protein containing meal; therefore, stable isotope load studies can be claimed to mimic physiologic events.

Confusion exists in both terminology and basic understanding of metabolic diseases causing elevation of the serum tyrosine level. Transient neonatal tyrosinemia may reach remarkably high levels without any symptoms. On the other hand, the elevation of serum tyrosine is only moderate in those babies with tyrosinemia who present with serious hepatorenal disease. Among the published reports regarding tyrosinemia are recorded eight older patients (including the two patients discussed here) who have very high serum tyrosine levels, but no evidence of liver or kidney disease $(1,5,12)$. Mental retardation has been a prominent feature, as have eye and skin lesions. However, considerable heterogeneity exists in the clinical features and biochemical findings. The term "nonhepatic tyrosinemia" is used to indicate the absence of liver damage in these patients - some have used the term "tyrosinosis," but this has also been used in other contexts.

Both patients studied in Melbourne have been reported previously. Their clinical features were different, but initial biochemical results were very similar. It was decided to study the metabolism of these two patients using isotope labeling techniques.

The administration of radioactive isotopes is not without risk to human subjects and is, therefore, only rarely suitable for in vivo metabolic studies. Substrates labeled with stable isotopes do not have this disadvantage, although deuterated compounds are known to produce deleterious biologic effects, as deuterium may be preferentially retained in vivo. The amounts of deuteriumlabeled tyrosine used in this study are not considered a health risk, as even complete isotope retention in vivo would increase the natural abundance of deuterium in the body by only less than $20 \%$.

The studies with deuterium-labeled substrates revealed striking differences between the two patients (a preliminary account of which has already been published (3)). The enzyme defect has been identified in one patient, but complete resolution in the other patient would necessitate surgical biopsy of the liver and this was not considered justified.

\section{CASE REPORTS}

Since both of these patients have been reported previously, only very brief clinical synopses are provided here.

$J L$, a 35-year-old mentally retarded male, has been an inmate of the Children's Training Centre, Kew, for most of his life. Nothing is known of his family history. His retardation is moderate, he is of relatively short stature $(151.5 \mathrm{~cm})$, and he has a marked tremor which is aggravated by attempts of fine manipulation. Earlier studies showed that the tremor was improved by a low tyrosine diet and was aggravated by the administration of $\mathrm{L}-$ 3,4-dihydroxyphenylalanine (L-DOPA). He was otherwise physically normal. The biochemical findings of earlier investigations were in close accord with those obtained in the present studies (12).

$P R$, an 11-year-old girl at the time of investigation, had been attending the Royal Children's Hospital since the age of 18 months because of recurring pseudoherpetic keratitis and persisting plantar and palmar hyperkeratosis (Richter-Hanhart syndrome). Separate reports of these two features have been published at an earlier stage by other authors $(1,17)$. She was 
referred for metabolic investigation after reports appeared linking this syndrome with tyrosinemia (5).

Her growth had always been quite normal as had her general physical health. Her school performance was lagging behind expectations by about 1 year, but this had been attributed to her persistent eye discomfort and her repeated absence from school. However, formal psychometric testing did indicate that her abilities were in the low normal range.

During the initial investigations deuterated tyrosine (829 $\mu \mathrm{mol} / \mathrm{kg}$ tyrosine in total, $663 \mu \mathrm{mol} / \mathrm{kg} \mathrm{D}$-tyrosine) was administered to $J L$ and $P R$ but caused a persistent rise in the serum tyrosine of only $P R$. Within an hour of administration of the load $P R$ complained of intense burning pain in her hands, feet, and eyes. During the next 2 or $3 \mathrm{hr}$ an acute inflammatory reaction developed around the hyperkeratotic lesions on the hands and feet. This took several days to subside. Twelve hours after a low phenylalanine, low tyrosine diet was commenced $P R$ excitedly announced that her hands, feet, and eyes felt comfortable for the first time in her memory. The eye lesions healed completed within a week and the skin lesions gradually cleared over 4 or 5 months so that there is now no detectable abnormality on the closest inspection. The dermal ridge pattern took almost 12 months to return to normal. $P R$ has now been maintained free of symptoms for 18 months on a diet based upon Albumaid XPT (20) allowing $220 \mu \mathrm{mol}$ phenylalanine and $220 \mu \mathrm{mol}$ tyrosine/ $\mathrm{kg} / 24 \mathrm{hr}$. She has continued to grow normally and has caught up with her school work to some extent.

One of the authors, a healthy 43-year-old male, served as a control subject for the deuterated tyrosine load study.

\section{METHODS}

All serum and urine samples were frozen immediately after collection and were held at $-20^{\circ}$ until used for measurements. Urine samples for catecholamine analysis were acidified $(10 \mathrm{ml} 6$ $\mathrm{N} \mathrm{HCl} / 2$ liters urine) before freezing. Urinary creatinine was determined by the Jaffe reaction. Quantitative results were means of duplicate preparations.

\section{URINARY FREE AROMATIC AMINO ACIDS}

2-Amino-n-octanoic acid $(100 \mu \mathrm{g})$ was added as an internal standard to $1 \mathrm{ml}$ urine and the solution was acidified to $\mathrm{pH} \mathrm{2-3}$. The urine was then passed through a column of cation exchange resin (Bio-Rad AG 50W-X2, 100-200 mesh, $500 \mathrm{mg}$ wet weight, $\mathrm{H}^{+}$form) and the column was washed with water. The amino acids were eluted with aqueous ammonia $(2 \mathrm{~N})$ and the eluate was dried under vacuum $\left(40^{\circ}\right)$.

The dried residue was derivatized for quantitative gas chromatography (GC) analysis by esterification under reflux $(45 \mathrm{~min}$, thionyl chloride-dry methanol reagent $(10 \%), 1 \mathrm{ml})$. After evaporation, derivatization was completed by the addition of dry pyridine $(300 \mu \mathrm{l})$, pivaldehyde $(50 \mu \mathrm{l})$, triethylamine $(100 \mu \mathrm{l})$, and molecular sieve (type 5A). N,O-Bis(trimethylsilyl)trifluoroacetamide (BSTFA) was added $30 \mathrm{~min}$ later $(100 \mu \mathrm{l})$, and after standing for a further $30 \mathrm{~min}$ a sample was injected onto the gas chromatograph (18). The recovery of tyrosine, phenylalanine, $p$-tyramine, and 2 -amino- $n$-octanoic acid by the above procedure was checked by extracting samples of urine spiked with known amounts of each of these compounds and derivatizing the extract. The percentage of recovery of each amino acid exceeded $95 \%$ as determined by GC using a peak height measurement.

A part of the dried amino acid residue was derivatized for measurement of the deuterium content of tyrosine by treatment with trimethylanilinium hydroxide in anhydrous methanol $(100$ $\mu \mathrm{l}, 0.1 \mathrm{~N})$ and pivaldehyde $(10 \mu \mathrm{l})$, in the presence of molecular sieve (type 3A), and pyrolytically esterifying the salt in the injector port of the gas chromatograph prior to GC-mass spectrometry (MS) analysis (19).

\section{URINARY CONJUGATED AROMATIC AMINO ACIDS}

The method used was based on that described by Kakimoto and Armstrong (7) in which the initial effluent and washings from the cation exchange resin were collected and hydrolyzed in $6 \mathrm{~N} \mathrm{HCl}$ at $100^{\circ}$ for $3 \mathrm{hr}$ after the addition of $100 \mu \mathrm{g} 2$-amino-noctanoic acid as internal standard. The hydrolysates were dried under vacuum $\left(40^{\circ}\right)$ and were then extracted and derivatized for GC analysis in the same manner as described for the free amino acids.

The recovery of $N$-acetyltyrosine and $p$-tyramine was checked as before by spiking urine samples with these compounds. In these experiments $N$-acetyltyrosine was added to the urine before the initial ion exchange treatment, whereas $p$-tyramine was added to the urine immediately before hydrolysis. The pereentage of recovery of these two compounds exceeded $90 \%$ as determined by GC (peak height).

\section{SERUM TYROSINE}

For measurement of the deuterium content of serum tyrosine, samples $(100 \mu l)$ were deproteinized by addition of ethanol (400) $\mu l)$ and centrifugation, after which the supernatant was drawn off and evaporated with nitrogen. The dried residue was derivatized as described under "Urinary Free Aromatic Amino Acids."

Serum tyrosine concentration was measured colorimetrically by the method of Udenfriend and Cooper (16) in which $0.5 \mathrm{ml}$ $30 \%$ trichloroacetic acid was added to $0.5 \mathrm{ml}$ serum which had been diluted with $1.5 \mathrm{ml}$ water. The mixture was allowed to stand for $10 \mathrm{~min}$ and was then centrifuged; $1.0 \mathrm{ml}$ of the supernatent was added to $0.5 \mathrm{ml}$ of 1 -nitroso-2-naphthol reagent $(0.1 \%$ in $95 \%$ ethanol) to which was then added $0.5 \mathrm{ml}$ of nitric acid reagent $(0.5 \mathrm{mg}$ sodium nitrite in $1.0 \mathrm{ml}$ of $20 \%$ aqueous nitric acid). The solution was stoppered and, after heating in a water bath at $55^{\circ}$ for $30 \mathrm{~min}, 5 \mathrm{ml}$ of redistilled ethylene dichloride were added. The mixture was then shaken and centrifuged at low speed, and the optical density of the top layer was read at $450 \mathrm{~nm}$.

\section{URINARY PIIENOLIC ACIDS}

Adipic acid $(100 \mu \mathrm{g})$ was added as an internal standard to 1 $\mathrm{ml}$ urine and the solution was acidified to $\mathrm{pH} 1$ with $0.1 \mathrm{ml} 6 \mathrm{~N}$ $\mathrm{HCl} ; 2 \mathrm{ml}$ saturated aqueous $\mathrm{NaCl}$ were then added. The mixture was extracted with ethylacetate $(3 \times 2 \mathrm{ml})$, and the organic extracts were pooled and dried over anhydrous magnesium sulfate. After filtering, the solution was evaporated to dryness with dry nitrogen. The dried residue was derivatized for GC analysis with BSTFA $(100 \mu \mathrm{l})$ followed by heating to $70^{\circ}$ for 30 $\min (4)$.

To ensure quantative recoveries of organic acids, urine extracts were prepared as quickly as possible after collection. However, circumstances caused some samples to be held at $-20^{\circ}$ for several weeks before extraction. GC response factors were determined using authentic compounds (21) which had been stored at $-20^{\circ}$. The recovery of $p$-hydroxyphenylacetic acid (PHPAA), p-hydroxyphenyllactic acid (PHPLA), p-hydroxyphenylpyruvic acid (PHPPA), and adipic acid from urine was checked as before by spiking urine samples with known amounts of each compound. Recoveries exceeded $95 \%$ and were determined by GC peak height measurements of the trimethylsily? derivatives.

\section{GAS CHROMATOGRAPHY}

This was carried out on a Packard-Becker 419 gas chromatograph using a glass column $(6$ feet $\times 0.25$ inch $)$ packed with $3 \%$ Apiezon $\mathrm{N}$ on dimethyldichlorosilane-treated Chromasorb W. A nitrogen flow rate of $25 \mathrm{ml} / \mathrm{min}$ was used, and during the analy- ses the temperature was programmed from $100^{\circ}$ to $250^{\circ}$ at a rate of $6 \% \mathrm{~min}$. 


\section{IIDENTIFICATION OF COMPOUNDS}

The identification of urinary metabolites was confirmed by combined GC-MS. Two GC-MS machines were available for this work; the first was an Aerograph HiFy (600D) GC interfaced, via a Watson-Biemann separator, to a computer-operated EAI (30)D) quadrupole mass spectrometer. The second was a Varian Aerograph $(2700)$ GC, interfaced via a jet separator to a Dupont 491B magnetic sector mass spectrometer fitted with a dual electron ionization/chemical ionization source.

\section{MEASUREMENT OF DEUTERIUM CONTENT}

Measurement of the deuterium content of PIIPAA, PHPLA, PHPPA and tyrosinc was made during GC-MS by examining each mass spectrum and selecting an intense ion containing the deuterium label. Measurement of the relative intensities of the nondeuterated $\left(D_{0}\right)$, monodeuterated $\left(D_{1}\right)$, and dideuterated (D.2) peaks were then made on this ion. Initially, short manual scans across limited mass ranges were taken, and the peak heights were measured by hand. The precision of isotope measurement was greatly improved by programming the quadrupole mass spectrometer to operate in a mass fragmentometry mode with settings optimized for isotope measurement. With the rapid automatic scan it was possible to accumulate many measurements of relative peak heights from which mean values were calculated. The results were expressed as the percentage of the deuterated species represented of the total $\left(D_{2} \times 100 /\left(D_{0}+D_{1}\right.\right.$ $\left.+D_{2}\right)$ ), and a correction was made for the intensity of the $D_{2}$ satelite ion in the nondeuterated compound. The quantity of recovered deuterated tyrosine or deuterated tyrosine metabolite, in micromoles per $\mathrm{kg}$ body weight or in micromoles per liter of serum, was then calculated by multiplying the percentage of deuterium label by the amount of metabolite present in the sample.

Table 1 lists the ion fragments of tyrosine and tyrosine metabolites used for deuterium measurements.

\section{PREPARATION OF DIEUTERATED L-TYROSINE}

L-Tyrosine ( $7 \mathrm{~g}$ ) was refluxed for $4 \mathrm{hr}$ in $4 \mathrm{~N} \mathrm{DCl}$ in $\mathrm{D}_{2} \mathrm{O}(40$ $\mathrm{ml}$ ), and after cooling to $0^{\circ}$, the tyrosine was precipitated by adjusting the solution to a $\mathrm{pH}$ of 5.5 with ammonia. The precipitate was collected by filtration and the tyrosine crystallized from a minimal quantity of boiling water. The crystals were filtered off, washed with ethanol, and dried in a dessicator. The identity of the product was confirmed by mass spectrometry as tyrosine containing 2 deuterium atoms in the tropylium ion $(\mathrm{m} / \mathrm{e} 93)$. The positions of the deuterium atoms in the aromatic ring were both shown to be ortho to the phenolic hydroxyl function by nuclear magnetic resonance (13). In a control experiment extending over a 24-hr period the deuterium label was shown to be stable in acid media $(1 \mathrm{~N} \mathrm{HCl})$ at $38^{\circ}$. The deuterated tyrosine substrate used for the loading studies consisted of $80 \%$ dideuterated species (D.-tyrosine) $19 \%$ monodeuterated species. and 1\% unlabeled tyrosine.

\section{TYROSINE AMINOTRANSFERASE ASSAY}

The method was an adaption of that described by Granner and Tomkins (6). The reaction mixture $(0.33 \mathrm{ml})$ contained $\alpha$-ketoglutarate $(3 \mu \mathrm{mol})$, pyridoxal-5-phosphate $(0.05 \mu \mathrm{mol})$, potassium phosphate buffer. pH $7.6(30 \mu \mathrm{mol})$, and L-tyrosine $(0.96$ $\mu \mathrm{mol})$. The mixture was preincubated at $37^{\circ}$ for $5 \mathrm{~min}$ and started by addition of dialyzed homogenate $(0.03 \mathrm{ml})$ prepared as described below. After 5 min the reaction was stopped by the addition of $\mathrm{KOH}(10 \mathrm{~N} .0 .02 \mathrm{ml})$. The solution was kept at $37^{\circ}$ for a further $30 \mathrm{~min}$, then the optical density was read at $331 \mathrm{~nm}$ against a zero time blank. Specific activity was expressed as the amount of PHPPA (in micromoles) produced per min per mg protein.

\section{p-HYDROXYPHENYLPYRUVIC ACID OXIDASE ASSAY}

The reaction was performed in two steps. Step 1 was the conversion of L- $\left[{ }^{14} \mathrm{C}\right]$ tyrosine to the substrate, $\left({ }^{14} \mathrm{C}\right]$ PHPPA (6). The reaction mixture $\left(\mathrm{RM}_{1}, 0.9 \mathrm{ml}\right)$ contained L-tyrosine $(5.6$ $\mu$ mol). potassium phosphate buffer. pH $7.6(100 \mu \mathrm{mol}), \alpha-$ ketoglutarate (10 $\mu \mathrm{mol})$. pyridoxal-5-phosphate (0.05 $\mu \mathrm{mol})$. and $\mathrm{L}-\left.\right|^{1 .} \mathrm{C} \mid \mathrm{tyr}$ rosine $(2.5 \mu \mathrm{Ci})$. After a 5 -min preincubation at $37^{\circ}$ the reaction was started by addition of tyrosine aminotransferase $(0.1 \mathrm{ml}, 2.5 \mathrm{mg} / \mathrm{ml}$, purified as described by Granner and Tomkins (6) and incubated at $37^{\circ}$ for $5 \mathrm{~min}$. Step 2 was the assay of PIIPPA oxidase in which the reaction mixture $\left(\mathrm{RM}_{2},(0.3 \mathrm{ml})\right.$ contained potassium phosphate buffer. pH 6.3 (25 $\mu$ mol), ascorbic acid $(1 \mu \mathrm{mol}), \alpha, \alpha$-dipyridyl $(0.8 \mu \mathrm{mol})$, and glutathione $(8 \mu \mathrm{mol})$. When incubation of $\mathrm{RM}_{1}$ was completed $0.2 \mathrm{ml}$ wats added to RM.2 (preincubated for $5 \mathrm{~min}$ ) followed by liver homogenate (0.2 ml. prepared from $50 \mathrm{mg}$ of tissuc $/ \mathrm{ml}$ of $0.14 \mathrm{M} \mathrm{KCl}$ containing $10^{-3} \mathrm{M}$ EDTA) which had been dialyzed against $0.125 \mathrm{M}$ potassium phosphate buffer (pH 7.0). After 20 min the

Table 1. Compounds and respective ion fragments on which deuterium measurements were made

\begin{tabular}{|c|c|c|c|c|}
\hline Compound & Derivaltive & Fragment $\left(D_{11}\right)$ & $\mathrm{m} / \mathrm{c}$ & $\mathrm{RI}(\%)^{2}$ \\
\hline Tyrosine & $-\mathrm{CH}_{2}-\mathrm{CH}^{2}-\mathrm{N}=\mathrm{CH}-\mathrm{C}\left(\mathrm{CH}_{3}\right)_{3}$ & $\mathrm{CH}_{3} \mathrm{O}-$ & $121\left(M^{+}-156\right)$ & 92 \\
\hline $\begin{array}{l}p \text {-Hydroxyphen- } \\
\text { ylacetic acid }\end{array}$ & $\left(\mathrm{CH}_{3}\right)_{3} \mathrm{Si}-\mathrm{O}-\bigcirc-\mathrm{CH}_{2}-\mathrm{COOSi}\left(\mathrm{CH}_{3}\right)_{3}$ & $\left(\mathrm{CH}_{3}\right)_{3} \mathrm{SiO}-$ & $179\left(\mathrm{M}^{+}-117\right)$ & 30 \\
\hline $\begin{array}{l}p \text {-Hydroxyphen- } \\
\text { yliatic acid }\end{array}$ & $\left(\mathrm{CH}_{3}\right)_{3} \mathrm{SiO}-\left.\right|_{\mathrm{OSi}\left(\mathrm{CH}_{3}\right)_{3}} ^{\mathrm{CH}}-\mathrm{COOSi}\left(\mathrm{CH}_{3}\right)_{3}$ & $\left(\mathrm{CH}_{3}\right)_{i} \mathrm{SiO}-\mathrm{C}$ & $179\left(\mathrm{M}^{+}-219\right)$ & 100 \\
\hline $\begin{array}{l}p-\text { Hydroxyphen- } \\
\text { ylpyruvic acid }\end{array}$ & $\left(\mathrm{CH}_{3}\right)_{3} \mathrm{SiO}-C \mathrm{OS}-\mathrm{CH}=\left.\right|_{\mathrm{OSi}\left(\mathrm{CH}_{3}\right)_{3}} ^{\mathrm{C}}-\mathrm{COOSi}\left(\mathrm{CH} \mathrm{H}_{3}\right)_{3}$ & Structure uncertain & $325\left(\mathrm{M}^{+}-71\right)$ & 25 \\
\hline
\end{tabular}

1 Measurements were made on the relative intensities (RI) of the listed fragments $\left(D_{6}\right)$ and the corresponding monodeuterated $\left(D_{1}\right)$ and dideuterated $\left(D_{2}\right)$ species.

"Refers to the intensity of each fragment ion $\left(D_{11}\right)$ as a percentage of the most intense ion in each mass spectrum. 
reaction was stopped by addition of trichloroacetic acid (10\%. $0.1 \mathrm{ml}$ ). A blank was run with trichloroacetic acid added to $\mathrm{RM}_{1}$ before incubation.

After freezing the supernatants $(100) \mu \mathrm{l})$ were chromatographed on Whatman SG81 (40 hr) or $3 \mathrm{MM}(16 \mathrm{hr})$ with watersaturated $n$-butanol containing $0.1 \%$ formic acid (9). This allowed separation of homogentisic acid from tyrosine and PHPPA. Homogentisic acid side marker was detected by staining with ammoniacal silver nitrate (9). and the chromatogram was run in the second dimension in water $(3 \mathrm{hr})$. The homogentisic acid spot was then located with ammoniacal silver nitrate. and this was cut into $2.6-\times 1.9-\mathrm{cm}$ rectangles for radioactive counting. The results are expressed as radioactive counts in homogentisic acid per 20 min per mg protein.

\section{RESULTS}

\section{BIOCHEMICAL ABNORMALITIES OF PATIENTS}

Initial biochemical findings on an unrestricted diet are listed in Table 2. Serum tyrosine was grossly increased and both excreted massive amounts of $p$-hydroxyphenolic acids. Excretion of $N$ acetyltyrosine was increased. Neither patient had any evidence of liver or kidney discase, and serum and urinary levels of methionine were normal. The amounts of free and conjugated $p$ tyramine in 1-ml samples of urine from both patients were below the limits of detection by GC-MS.

\section{D:-TYROSINE LOAD STUDIES BEFORE TREATMENT}

In the initial studies, performed on the two patients before any dictary treatment was given and on the normal control subject. each subject ingested $663 \mu$ mol $D_{2}$-tyrosine/kg body weight after an 8-hr fast. The tyrosine was dissolved with the minimum acidification necessary to achieve solubility in approximately 100 ml water. Toast and a fruit juice drink were allowed along with the load. The study of $P R$ was performed first and was continued for only $24 \mathrm{hr}$. After examining the results all other studies were continued for $48 \mathrm{hr}$. The total recovery of the two deuterium labels in the phenolic ring of tyrosine and tyrosine metabolites (henceforth referred to as the $\mathrm{D}_{2}$-phenolic moiety) in the urine of the three subjects is summarized in Table 3 . The total recovery was much greater in the two patients than in the control subject. All three $p$-hydroxyphenolic acids were present and were heavily labeled in the patients, but only PIPAA was present and contained significant labeling in the control. Detailed consideration of these results is presented later after allowing for differences in tyrosine pools.

The urinary output of deuterated catecholamines, i.e., 3,4dihydroxyphenylethylamine (dopamine), adrenalin, and noradrenalin, were also determined by GC-MS using the volatile $N$ trifluoroacetyl- $O$-trimethylsilyl derivatives of these compounds, but because of the relatively small total production of these metabolites, the results have not been included in this table as they account for less than $0.1 \%$ of the total recovery in the urine of the D:-phenolic moiety. The urinary output of deuterated $N$ acetyltyrosine was not determined because the relatively small total production of this metabolite would account for less than $3 \%$ of the total recovery in the urine of the $D_{2}$-phenolic moiety.

Another difference between the control and $J L$ is apparent in Table 3 . The control subject excreted the vast majority of the recovered label in the first $24 \mathrm{hr}$ and very little in the next day. $J L$ continued to excrete substantial amounts of the label in the

Table 2. Biochemical features of patients on unrestricted dicts

\begin{tabular}{|c|c|c|c|}
\hline & \multicolumn{3}{|c|}{ Subject } \\
\hline & $J L$ & $P R$ & Maximum of normal range \\
\hline Serum tyrosine concentration (mmol/liter) & 1.36 & 1.52 & 0.06 \\
\hline \multicolumn{4}{|l|}{ Urinary metabolites ( $\mathrm{mmol} / \mathrm{mmol}$ creatinine) } \\
\hline Tyrosine & 0.121 & 0.177 & 0.011 \\
\hline$N$-Acetyltyrosine & 0.067 & 0.034 & 0.002 \\
\hline p-Iydroxyphenylacetic acid & 0.177 & 0.136 & 0.015 \\
\hline$p$-Hydroxyphenyllactic acid & 1.54 & 0.851 & Not detected \\
\hline$p$-Hydroxyphenylpyruvic acid & 1.41 & 0.142 & Not detected \\
\hline 3,4-Dihydroxyphenylalanine (DOPA) (22) & $0.408 \times 10^{-3}$ & Normal & $0.038 \times 10^{-3}$ \\
\hline Dopamine & $2.63 \times 10^{-3}$ & Normal & $1.23 \times 10^{-3}$ \\
\hline Noradrenalin & Normal & Normal & $0.267 \times 10^{-3}$ \\
\hline Adrenalin & Normal & Normal & $0.082 \times 10^{-3}$ \\
\hline
\end{tabular}

Table 3. Recovery of deuterated metabolites in urine from patients $J L$ and PR before dietary treatment and from normal subject after deuterated $\left(D_{2}\right)$-tyrosine oral load

\begin{tabular}{|c|c|c|c|}
\hline & \multicolumn{3}{|c|}{ Subject } \\
\hline & $J L$ & $P R$ & Normal \\
\hline $\begin{array}{l}\text { Initial serum tyrosine concentration (mmol/li- } \\
\text { ter) }\end{array}$ & 1.37 & 1.52 & 0.07 \\
\hline Oral load $\mathrm{D}_{2}$-tyrosine ( $\mu \mathrm{mol} / \mathrm{kg}$ body weight) & 663 & 663 & 663 \\
\hline Recovered in urine ( $\mu$ mol/kg body weight) & $(0-48 \mathrm{hr})$ & $(0-24 \mathrm{hr})$ & $(0-48 \mathrm{hr})$ \\
\hline $\mathrm{D}_{2}$-Tyrosine & 6.32 & 7.31 & 0.50 \\
\hline$D_{2}-p$-Hydroxyphenylacetic acid & 6.78 & 5.92 & 2.48 \\
\hline$D_{2}-p$-Hydroxyphenyllactic acid & 51.15 & 29.04 & 0.04 \\
\hline$D_{2}-p$-Hydroxyphenylpyruvic acid & 46.60 & 2.58 & Not detected \\
\hline Total & 110.85 & 44.85 & 3.02 \\
\hline \multicolumn{4}{|l|}{ Total as $\%$ of ingested } \\
\hline $0-24 \mathrm{hr}$ & 11.70 & 6.7 & 0.44 \\
\hline $0-48 \mathrm{hr}$ & 16.7 & & 0.46 \\
\hline
\end{tabular}


second $24 \mathrm{hr}$. It is particularly unfortunate that the study on $P R$ ceased at $24 \mathrm{hr}$, because her serum results suggest extremely slow disposal of the load.

The total serum tyrosine concentration and the concentration of $\mathrm{D}_{2}$-tyrosine in the serum were both measured. The total tyrosine concentration rose to very high levels indeed in $P R$ and were still not back to preload levels 7 days later. The rises observed in $J L$ and in the control were smaller and more transient (Fig. 1, $B$ and $D$ ).

The initial rate of appearance of $D_{2}$-tyrosine in the serum was very similar in all three subjects, but both patients differed from the control subject in that the $D_{2}$-tyrosine concentration continued to rise up to $8 \mathrm{hr}$ after the load (Fig. 1, $A$ and $C$ ).

All of these results indicated striking differences between the patients and the normal control subject, but less impressive differences between the two patients.

\section{D.-TYROSINE LOAD TEST AFTER DIETARY CONTROL}

A remarkable difference in the tyrosine metabolism of the two patients became apparent after a second series of experiments performed after the serum tyrosine concentration had been lowered through restriction of the dietary intake of phenylalanine and tyrosine. A smaller load of $D_{2}$-tyrosine $(221 \mu \mathrm{mol} / \mathrm{kg}$ body weight) was used.

The total recovery of the $D_{2}$-phenolic moiety in the urine of the two patients in this series of experiments is shown in Table 4. The results in $J L$ are very similar to those of the original test, but the handling of the labeled tyrosine has changed to nearly normal in $P R$.

A summary of the recovery results from the five experiments with D.-tyrosine loads is given in Table 5. Comparisons of the raw data of recovery of label between the subjects in the two series of experiments are confounded to some extent by differences in serum tyrosine pool sizes. In Table 5 the data has been transformed by correcting for the initial serum tyrosine concentration (indicating the tyrosine pool), allowing a more valid comparison of the five studies.

This comparison clearly shows that $J L$ metabolized the label poorly at high or low serum tyrosine levels. However, the disposal of label in $P R$ improved dramatically when the serum tyrosine level was lowered.

Mcasurement of the concentration of $D_{2}$-tyrosine in the serum of the patients after the second oral load of $D_{2}$-tyrosine is shown
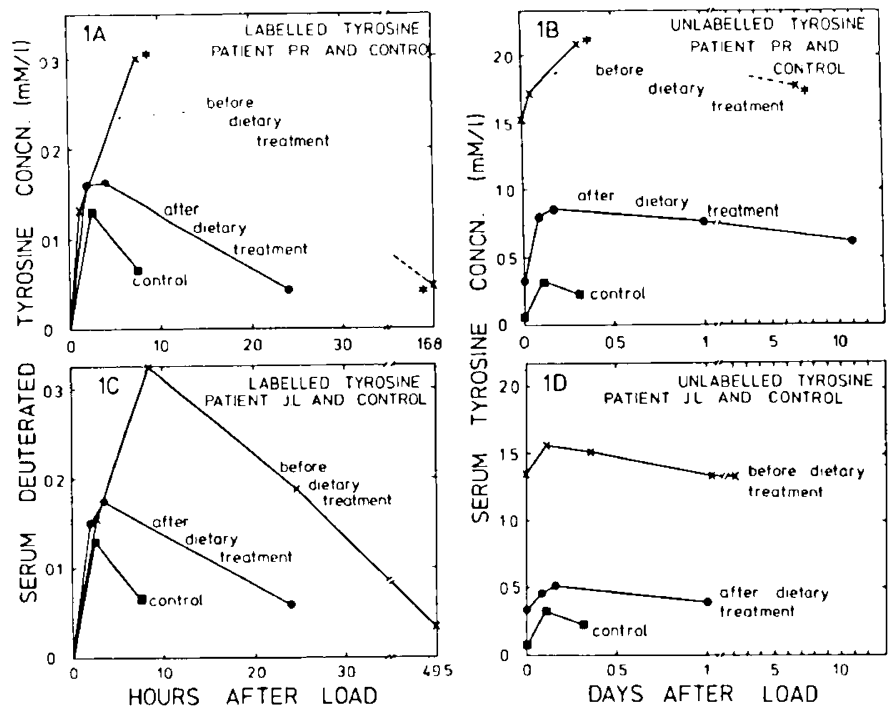

Fig. 1. Changes in serum tyrosine concentration and serum deuterated tyrosine concentration in patients $J L$. and $P R$, before and after dietary treatment, and in a normal control subject, after oral loads of deuterated tyrosine.*: because no serum samples were collected during this time period these points have not been connected by a continuous line.
Table 4. Recovery of deuterated metabolites in urine from patients $P R$ and $J L$ after dietary treatment after reduced deuterated $\left(D_{2}\right)$ tyrosine oral load

\begin{tabular}{|c|c|c|}
\hline & \multicolumn{2}{|r|}{ Subject } \\
\hline & $J L$ & $P R$ \\
\hline $\begin{array}{l}\text { Initial serum tyrosine concen- } \\
\text { tration }(\mathrm{mmol} / \mathrm{liter})\end{array}$ & 0.33 & 0.33 \\
\hline $\begin{array}{l}\text { Oral load } \mathrm{D}_{2} \text {-tyrosine ( } \mu \mathrm{mol} / \mathrm{kg} \\
\text { body weight) }\end{array}$ & 221 & 221 \\
\hline $\begin{array}{l}\text { Recovered in urine ( } \mu \mathrm{mol} / \mathrm{kg} \\
\text { body weight) }\end{array}$ & $0-48 \mathrm{hr}$ & $0-48 \mathrm{hr}$ \\
\hline$D_{2}$-Tyrosine & 2.64 & 0.55 \\
\hline $\mathrm{D}_{2}-p$-Hydroxyphenylacetic acid & 5.70 & 0.40 \\
\hline $\mathrm{D}_{2-p-\text { Hydroxyphenyllactic acid }}$ & 50.06 & Not detected \\
\hline$D_{2}-p$-Hydroxyphenylpyruvic acid & 16.08 & Not detected \\
\hline Total & 74.48 & 0.95 \\
\hline \multicolumn{3}{|l|}{ Total as \% of ingested } \\
\hline $0-24 \mathrm{hr}$ & 26.50 & 0.40 \\
\hline $0-48 \mathrm{hr}$ & 33.70 & 0.43 \\
\hline
\end{tabular}

in Figure 1, $A$ and $C$, and changes in total serum tyrosine concentration are shown in Figure $1, B$ and $D$. Once again $J L$ 's results followed a pattern similar to the previous study, whereas the pattern in $P R$ approximates that obtained in the control subject.

\section{ENZYME ASSAY RESULTS}

The results of the enzyme assays performed on needle biopsy samples are shown in Table 6 . The small amount of tissue available $(15-20 \mathrm{mg})$ limited the precision of the assay as experiments could not be repeated for confirmation of results.

The PHPPA oxidase assay gave no result in $P R$ and there was no tissue available to repeat the test. The two chromatographic systems gave different results in $J L$. There was no doubt that the spot counted on SG81 was homogentisic acid. It is more difficult to guarantec separation of homogentisic acid from all other radioactive prescursors or products. Consequently, the results are interpreted as showing severe deficiency of enzyme activity.

The tyrosine aminotransferase assay showed definite activity in both patients which was quantitated only in $J L$.

\section{DISCUSSION}

In comparing the results of $\mathrm{D}_{2}$-tyrosine loading in the patients and in the normal control subject it seems reasonable to assume that disposal of tyrosine in protein synthesis and in conversion to thyroxine, melanin, and catecholamines is fairly constant and that the differences observed reflect mainly the variation in oxidation of the tyrosine carbon skeleton.

Excretion of the intact $D_{2}$-phenolic moiety was grossly excessive in both patients when tested before dietary treatment, indicating a marked impairment of the oxidative pathway. This situation persisted after lowering the serum tyrosine by dietary means in $J L$ and it was not surprising to find low levels of PHPPA oxidase in his liver biopsy. The results obtained using the two different chromatography systems did not agree very satisfactorily. However, spurious increase in the result (because of failure to separate homogentisic acid from some other labeled metabolite) is more probable than a falsely low result.

The dramatic change observed in the effect of $D_{2}$-tyrosine load after lowering of the serum tyrosine in $P R$ suggests that the high initial serum tyrosine level was inhibiting the function of PHPPA oxidase in vivo. Unfortunately, the enzyme assay performed on the needle liver biopsy did not succeed in definitely ruling out an intrinsic defect in this enzyme. An alternate proposal might be the existence of a genetic defect in PHPPA oxidase with a degree 
Table 5. Summary of five experiments with deuterated (D.2)-tyrosine loads: Recovery of urinary de'uterated tyrosine and tyrosine metabolites

\begin{tabular}{|c|c|c|c|c|c|}
\hline \multirow[b]{3}{*}{ Initial serum tyrosine concentration (mmol/liter) } & \multicolumn{5}{|c|}{ Subject } \\
\hline & \multicolumn{2}{|c|}{$J L$} & \multicolumn{2}{|c|}{$P R$} & \multirow{2}{*}{$\frac{\text { Normal }}{0.07}$} \\
\hline & 1.37 & 0.33 & 1.52 & 0.33 & \\
\hline Oral load $D_{2}$-tyrosine ( $\mu$ mol/kg body weight) & 66,3 & 221 & 663 & 221 & 66.3 \\
\hline Recovered in urine: time period $(\mathrm{hr})$ & $0-48$ & $0-48$ & $0-24$ & $0-48$ & $0-48$ \\
\hline $\begin{array}{l}\text { Total D.-phenolic moiety ( } \mu \text { mol } / \mathrm{kg} \text { body } \\
\text { weight) }\end{array}$ & 110.85 & 74.48 & 44.85 & 0.95 & 3.02 \\
\hline Total $D_{2}$-phenolic moiety as $\%$ of oral load & 16.7 & 3.7 .70 & 6.7 & 0.43 & 0.46 \\
\hline Total $D_{2}$-phenolic moicty corrected ${ }^{1}$ as a $c_{0}$ & 22.9 & 11.1 & 10.3 & 0.14 & 0.03 \\
\hline
\end{tabular}

${ }^{1}$ Corrected for initial serum tyrosine concentration and calculated as total recovery $\times 100$
total oral load/initial serum tyrosine concentration

Table 6. Enzlome assay resuls

\begin{tabular}{|c|c|c|c|}
\hline & \multirow{2}{*}{ Tyrosine aminotransferasc } & \multicolumn{2}{|c|}{ PIIPPA oxidase" chromatography on } \\
\hline & & SG81 & $3 \mathrm{MM}$ \\
\hline Rat liver & 7.7 & & \\
\hline Control human liver (autopsy) & 4.7 & 19.6 & 16.6 \\
\hline$J L$ liver (needle biopsy) & 3.3 & 0 & 6.4 \\
\hline$P R$ liver (needle biopsy) & $\begin{array}{l}\text { Activity present but not } \\
\text { quantitated }\end{array}$ & Not tested & Not tested \\
\hline
\end{tabular}

${ }^{1}$ Micromoles of $p$-hydroxyphenylpyruvic acid (Pllpps) produced per min per mg protein.

2 Radioactive counts in the homogentisic acid area of the paper chromatogram per 20 min per mg protein.

of residual activity which is substantially greater than that present in $J L$. Under such a circumstance there might be a difference in the handling of $D_{2}$ load at different serum tyrosine levels. The fact that the second load test was performed with a lower load might particularly suggest this explanation. However, it must be remembered that the same lower load was used when testing $J L$ after dietary treatment and that the results in Table 5 are corrected for tyrosine pool size.

The present data cannot absolutely distinguish between these two possibilities, but the degree of change seems more compatible with the suggestion of substrate inhibition. The extraordinarily slow disposal of the initial $D_{2}$-tyrosine load by $P R$ (the $D_{2-}$ tyrosine was still detectable in her serum after 7 days) seems incompatible with the suggestion of a mild constant defect in PHPPA oxidase. PHPPA oxidase has been shown to be susceptible to substrate inhibition in virro $(10,11)$. Scriver (15) has already postulated substrate inhibition to explain the accumulation of both the metabolic products and the substrate of the defective enzyme in a patient with deficient hepatic cytosol tyrosine aminotransferase described by Kennaway and Buist (8). This patient suffered skin and eye lesions identical to those present in $P R$. The matter can only be finally resolved by a deuterated load test in Kennaway and Buist's patient, or by a more satisfactory enzyme assay in $P R$. A $D_{2}$-tyrosine load given to a normal control subject at high serum tyrosine levels might achieve the same end but there is no easy method of achieving a consistent tyrosine level of the magnitude necessary in a normal control subject.

If substrate inhibition is truly the explanation in this patient it is most interesting to note the severe degree of metabolic block produced by this secondary effect compared to the rather minor interference with tyrosine disposal apparently attributable to the basic enzyme defect.

The negligible formation of deuterated $N$-acetyltyrosine and deuterated $p$-tyramine in both patients contrasts with findings in some of the previously described cases (see Reference 5) and with a recent claim that this becomes the major pathway of disposal of tyrosine under circumstances of high load in mice (2). One should not be too surprised by differences in byproducts of accumulating metabolites in different patients with the same basic metabolic block for genetic heterogeneity is great in normal humans and must cause differences in the capacity of these minor pathways.

The pattern of accumulating metabolic products was very similar in $J L$ and $P R$, yet the basic lesion proved to be very different. $J L$ did excrete greater amounts of PHPPA than $P R$ but we are loathe to place great significance on the former without extensive investigation of the rate of chemical conversion of PHPPA to PHPAA and PHPLA under the conditions of storage. One might hope that the results in these patients and the points just discussed may deter those who imagine that they can resolve the metabolic defect in Grace Medes' classic patient (14) retrospectively.

On the other hand, the increased levels of DOPA and dopamine may be responsible for the tremor which was a major symptom in $J L$. Administration of L-DOPA increased the tremor (12) and the tremor diminished when the serum tyrosine level was lowered by detary means during this study. The precise cause of the mental retardation which has been a prominent feature of most of the reported patients is not clear and it is impossible to predict whether early dietary treatment would prevent this defect. However, the relationship between serum tyrosine levels and the skin and eye lesions was very direct in $P R$. Elevation of the serum level caused an acute increase in the lesions and the pain in them was abolished very rapidly when the diet was started.

\section{CONCLUSION}

Metabolic studies on two patients with rare forms of nonhepatic tyrosinemia, using deuterated tyrosine loads, resolved an anomalous situation in which the two patients had different clinical symptoms but similar biochemical abnormalities.

One patient, an institutionalized mentally retarded male who had a marked tremor of the head. hands. and feet. was found to be suffering from a defective $p$-hydroxyphenylpyruvic acid oxidase system. The results of enzyme assays on needle liver biop- 
sies were not very satisfactory, but did support this finding. In this patient urinary excretion of tyrosine, and particularly the phenolic metabolites of tyrosine. was grossly elevated. Although this situation persisted after dietary treatment. some improvement in his behavior was noticed. particularly with respect to the loss of tremor.

The other patient, an 11-year-old girl of low normal intelligence with chronic palmar and plantar keratosis and recurrent pseudoherpetic keratitis, suffered from substrate inhibition of $p$ hydroxyphenylpyruvic acid oxidase when on a normal diet. Resolution of the clinical and biochemical symptoms and disappearance of the inhibition of $p$-hydroxyphenylpyruvic acid oxidase occurred after administration of a diet low in phenylalanine and tyrosine. The fundamental metabolic defect in this patient has not been established, but the findings appear compatible with a defect in hepatic soluble tyrosine aminotransferase.

\section{REFERENCES AND NOTES}

1. Callan, N. J.: Circumscribed palmo-plantar keratoderma. Aust. J. Dermatol., 9: $76(1970)$.

2. David, J.-C., Dairman, W., and Udenfriend. S.: Decarboxylation to tyramine: A major route of tyrosine metabolism in mammals. Proc. Nat. Acad. Sci. U.S.A., 71: 1771 (1974).

3. Faull, K. F.. Gan, I., Halpern, B., and Danks, D. M.: The use of stable isotopes for the in vivo study of metabolic disorders. Proceedings of the Second International Conference on Stable lsotopes, Oak Brook, Illinois, October 1975 (Argonne National Laboratory, 111., in press.)

4. Gan, I., Korth, J., and Halpern, B.: Use of gas chromatography-mass spectrometry for the diagnosis and study of metabolic disorders. J. Chromatogr., 93: 435 (1974).

5. Goldsmith, L. A., Kang. E., Brenfang. D. C., Jimbow, K., Gerald, P., and Baden. H. P: Tyrosinemia with plantar and palmar keratosis and keratitis. J. Pediat., 83: 798 (1973).

6. Granner, D. K., and Tomkins, G. M: Tyrosine aminotransferase (rat liver) Mcthods Enzymol., 17(A): 633 (1970).

7. Kakimoto, Y., and Armstrong, M. D: The phenolic amines of human urine. J. Biol. Chem., 237: 208 (1962)

8. Kennaway, N.G., and Buist, N. R. M: Metabolic studies in a patient with hepatic cytosol tyrosine aminotransferase deficiency. Pediat. Res., 5: 287 (1971).

9. Knox, W. E., and LeMay-Knox. M.: The oxidation in liver of L-tyrosine to acetoacefate through $p$-hydroxyphenylpyruvate and homogentisic acid. Biochem. J., 49: 686 (1951).

10. LaDu, B. N.: The enzyme deficiency in tyrosinemia. Amer. J. Dis. Child. 113: 54 (1967).

11. LaDu, B. N., and Zannoni, V. G.: The tyrosine oxidizing system of liver. II Oxidation of $p$-hydroxyphenylpyruvic acid to homogentisic acid. J. Biol. Chem., 217: 777 (1955).

12. Louis, W. J., Pitt, D. D., and Davies, H.: Biochemical studies on a patient with tyrosinosis. Aust. N.Z. J. Med., 4: 281 (1974)

13. Martin, R. B., and Morlino, V. J.: Exchange of carbon bound hydrogen atoms ortho to the hydroxyl group of tyrosine. Science, 150: 493 (1965).

14. Medes, G.: A new error of tyrosine metabolism: Tyrosinosis. The intermediary metabolism of tyrosine and phenylalanine. Biochem. J., 26:917 (1932).

15. Scriver, C. R., and Rosenberg, L. E.: Amino Acid Metabolism and Its Disorders, pp. 338-369, (W. B. Saunders Co., Philadelphia, 1973).

16. Udenfriend, S., and Cooper. J. R.: The chemical estimation of tyrosine and tyramine. J. Bicl. Chem., 196: 227 (1952)

17. Westmore, R. and Billson. F. A.: Pseudoherpetic keratitis: Corneal changes in circumscribed palmo-plantar keratoderma. Brit. J. Ophthalmol., 57: 654 (1973).

18. Williams, K. M., and Halpern, B.: The use of gas chromatography-mass spectrometry for the diagnosis and study of metabolic disorders. Aust. J. Biol. Sci.. 26: 831 (1973).

19. Williams, K. M., and Halpern, B.: Gas chromatography of amino acids via pyrolysis methylation of neopentylidene trimethylanilinium salts. Ann. Lett.. 6: 839 (1973).

20. Scientific Hospital Supplies, Liverpool, England.

21. Sigma Chemical Co., St. Louis, Mo., U.S.A.

22. Figures for catecholamines were kindly supplied by Professor W. J. Louis, University of Melbourne, Department of Medicine, Austin Hospital, using a modification of the trihydroxyindole procedure (12).

23. We would like to thank Professor W. J. Louis and Dr. D. D. Pitt who made earlier studies on $J L$, and Dr. F. A. Billson who referred $P R$ for investigation. Expert technical assistance was supplied by Ian McNeice and John Korth who ran the GC-MS instruments.

24. In accordance with the Hclsinki agreement informed consent from the parents of $P R$ was obtained after full discussion. The Mental Health Department of Victoria, the legal custodians of $J L$, gave consent to these investigations. $J L$ himself willingly agreed to take part in the actual experiments although he is unable to comprehend their full implications.

25. This work was supported by grants from The National Health and Medical Rescarch Council of Australia.

26. Requests for reprints should be addressed to: Professor D. M1. Danks, Department of Pediatrics, Royal Children's Hospital, Flemington Rd., Parkville, Victoria 3052 (Australia).

27. Received for publication June 10, 1976 .

28. Accepted for publication September 22, 1976.

\title{
A Comparison of Fasting Plasma Insulin and Growth Hormone Concentrations in Marasmic, Kwashiorkor, Marasmic-Kwashiorkor and Underweight Children
}

\author{
H. ROBINSON, ${ }^{(36)}$, AND D. PICOU \\ Tropical Metabolism Research Unit, University of the West Indies, Kingston, Jamaica, West Indies
}

\section{Summary}

Fasting plasma insulin and growth hormone concentrations were measured in $\mathbf{2 4}$ marasmic, 11 kwashiorkor, 16 marasmickwashiorkor, and 4 underweight children. Hormone measurements were made by a special modification of the Hales and
Randle double antibody immunoassay with increased sensitivity in the concentration range $0-25 \mu \mathrm{U} / \mathrm{ml}$. Fasting plasma insulin was low in marasmus, kwashiorkor, and marasmic-kwashiorkor children, and increased to normal levels after recovery. Fasting plasma growth hormone was elevated in all groups during malnutrition and was significantly decreased to normal levels after 